\title{
Management of Non-High-Risk Salivary Gland Carcinomas With Surgery Alone
}

\author{
Sepehr Shabani ${ }^{1}$, Abhay V. Sharma ${ }^{1}$, Matthew L. Carmichael ${ }^{1}$, Tapan A. Padhya ${ }^{1}$, Matthew J. Mifsud ${ }^{1}$ \\ 1. Otolaryngology - Head and Neck Surgery, University of South Florida Morsani College of Medicine, Tampa, USA
}

Corresponding author: Sepehr Shabani, sshabani@usf.edu

\section{Abstract \\ Background}

Risk stratification and appropriate treatment selection are essential for the management of head and neck malignancies, in order to optimize long-term outcomes. Salivary gland carcinomas (SGCs) pose a particular challenge due to their extensive biologic heterogeneity. Primary surgical resection remains the mainstay of treatment; however, outcomes with single modality therapy for 'non-high-risk' lesions are less elucidated in the literature present on the subject. We present our experience with non-high-risk salivary gland malignancies treated by surgery alone.

\section{Methods}

A retrospective analysis of SGCs from 1998-2011 was completed after receiving Institutional Review Board approval. Patient demographic, tumor, treatment, and outcome data were obtained from chart review. The primary outcomes of interest were overall survival (OS) and recurrence-free survival (RFS).

\section{Results}

Of the 62 patients identified, 49 patients underwent resection of the primary tumor alone, while an ipsilateral selective neck dissection was included for 13 patients. The median follow-up was 5.05 years. Of the tumors, $79 \%$ were low-intermediate grade, $3 \%$ high grade, and $17 \%$ poorly classified. The OS and RFS were $91 \%$ and $87 \%$ at five years and $80 \%$ and $79 \%$ at 10 years, respectively. The combined failure rate of local, regional, and distance was $13 \%$.

\section{Conclusion}

Surgery alone is an appropriate treatment strategy for patients with non-high-risk salivary gland malignancy, affording a high likelihood of long-term RFS and OS.

Received 06/05/2021 Review began 06/08/2021 Review ended 07/29/2021 Published 08/07/2021

(๑) Copyright 2021

Shabani et al. This is an open access article distributed under the terms of the Creative Commons Attribution License CC-BY 4.0., which permits unrestricted use, distribution, and reproduction in any medium, provided the original author and source are credited.
Categories: Otolaryngology, Radiation Oncology, Oncology

Keywords: head and neck tumors, parotid tumor, submandibular neoplasm, adjuvant radiation therapy, malignancy surgery

\section{Introduction}

Salivary gland malignancies are a heterogenous group of neoplasms, with more than 24 different disease types categorized [1]. They are also relatively rare, a cause of only 3-7\% of head and neck cancers in the USA annually $[2,3]$. This rarity and histologic diversity pose an extensive clinical challenge, preventing the development of well-established/evidence-based treatment algorithms to best optimize treatment decisions. Nevertheless, surgical resection is an essential component to the primary treatment of these neoplasms when feasible $[4,5]$. Nonsurgical treatment strategies have typically been associated with decreased tumor control rates, often associated with a presumption of radio-resistance for the majority of salivary gland cancers (SGCs) $[3,5-8]$.

In addition to the standard American Joint Committee on Cancer (AJCC) tumor, nodes, and metastases (TNM) staging system, key clinicopathologic variables are often considered for risk stratification. Pioneering work by Foote and Frazell in the 1950s, for example, first linked distinct tumor histologies with unique disease phenotypes [4]. As our understanding of this collection of malignancies expands, prognostication schemes continue to evolve. Certain features, however, are almost universally accepted to be associated with aggressive clinical behavior, in particular, high-grade histology (if well defined), gross 'named nerve' invasion, advanced tumor size (>4cm), positive surgical margins, and cervical lymph node spread [1, 9, 10]. A multi-modality approach is the typical standard for these high-risk cases, with the addition of adjuvant radiotherapy (after surgery) affording enhanced disease control [3, 11]. Terhaard et al, for example, reported significant improvement in 10-year local disease control for advanced (T3-T4) cases when adjuvant radiotherapy was utilized compared to surgery alone (84\% vs $18 \%$ ) [12]. 
Much published research has similarly concentrated on high-risk SGCs, with non-high-risk cases often included or combined into large series as a relative afterthought. We thus present our own experience with non-high-risk salivary malignancies (non-angioinvasive, non-infiltrative) [13], managed with surgery alone. In reviewing the long-term results of our data, we hope to demonstrate the acceptable application of this management strategy.

This article was previously presented as meeting abstracts at two conferences (one national and one regional): the 2019 Combined Otolaryngology Spring Meeting-AHNS on May 1, 2019, and the 2019 Florida Combined Otolaryngology Meeting on November 8, 2019.

\section{Materials And Methods}

This study was approved by the Institutional Review Board of H. Lee Moffitt Cancer Center and Research Institute (Pro0000923). A retrospective chart review was performed on patients with either primary major or minor SGCs managed between 1998 and 2011. The year 2011 was chosen as the cutoff year to allow longterm follow-up, given that late recurrence is a common feature of many salivary malignancies. Chart review was performed and completed in June 2019.

Study inclusions were as followed: single modality surgical therapy (tumor resection \pm neck dissection) of the initial tumor with curative intent, absence of cervical lymph node spread (cN0 or pNO), no evidence of disease metastasis (M0), and a negative surgical margin (R0) after final pathological assessment. Squamous cell carcinomas arising within major salivary glands were excluded given the difficulty distinguishing this potential entity from metastatic cutaneous carcinomas. After identification of patients, the following information was gathered: demographics, age at diagnosis, date of surgery, tumor characteristics, status and date of locoregional recurrence, status and date of distance metastasis, date of last follow-up, and date of death (if appropriate). All cases were uniformly staged using AJCC seventh edition TNM guidelines.

Endpoints of interest were overall survival (OS) calculated from the date of surgery to the final patient contact or mortality and recurrence-free survival (RFS) calculated from the date of surgery to final follow-up with detail of disease status. All statistical analyses were performed using the Statistical Package for the Social Sciences (SPSS) Statistics Version 25.0 (IBM, Armonk, NY). Survival data was reported utilizing the Kaplan-Meier method. Comparisons were made with a log-rank test with a $\mathrm{p}$-value $<0.05$ considered for significance.

\section{Results}

After query of institutional data, 63 patients initially met inclusion criteria for this review; a single patient was, however, excluded due to a suicide on post-op day two, leaving a total of 62 cases. Patient and disease characteristics are listed in Table 1. Of the selected patients, 34 (55\%) were female and 28 (45\%) were male. The median age at diagnosis was 60 years with females presenting at a younger age compared to males (57 vs. 60). Forty-nine patients underwent resection of the primary tumor alone, while an ipsilateral selective neck dissection was included for 13 patients who invoked a concern for high-grade tumors on fineneedle aspiration/intra-operative frozen section or cervical lymphadenopathy on pre-operative imaging. The median follow-up was 5.05 years. 


\section{Cureus}

\begin{tabular}{|c|c|c|c|}
\hline \multirow{2}{*}{ Median Age (Years) } & Female & \multicolumn{2}{|l|}{57} \\
\hline & \multirow[t]{2}{*}{ Male } & \multicolumn{2}{|l|}{60} \\
\hline & & Number of Patients & Percentage of Patients (\%) \\
\hline \multirow{2}{*}{ Gender } & Female & 34 & 55 \\
\hline & Male & 28 & 45 \\
\hline \multirow{8}{*}{ Tumor Site } & Major Salivary Glands & 17 & 27 \\
\hline & Parotid & 14 & 23 \\
\hline & Submandibular & 3 & 5 \\
\hline & Minor Salivary Glands & 45 & 73 \\
\hline & Oral cavity & 30 & 48 \\
\hline & Oropharynx & 10 & 16 \\
\hline & Sinonasal & 4 & 6 \\
\hline & Larynx & 1 & 2 \\
\hline \multirow{3}{*}{ Tumor Grade } & Low-Intermediate & 49 & 79 \\
\hline & Poorly classified & 11 & 18 \\
\hline & High & 2 & 3 \\
\hline \multirow{10}{*}{ Histology } & Mucoepidermoid carcinoma & 26 & 42 \\
\hline & Adenoid cystic carcinoma & 11 & 18 \\
\hline & Acinic cell carcinoma & 10 & 16 \\
\hline & Polymorphous low-grade adenocarcinoma & 5 & 8 \\
\hline & Adenocarcinoma & 4 & 6 \\
\hline & Carcinoma ex-pleomorphic adenoma & 2 & 3 \\
\hline & Oncocytic carcinoma & 1 & 2 \\
\hline & Salivary duct carcinoma & 1 & 2 \\
\hline & Basal Cell adenocarcinoma & 1 & 2 \\
\hline & Adenosquamous carcinoma & 1 & 2 \\
\hline \multirow{3}{*}{ T-Classification } & 1 & 49 & 79 \\
\hline & 2 & 8 & 13 \\
\hline & 3 & 5 & 8 \\
\hline
\end{tabular}

TABLE 1: Demographic, tumor, and clinical characteristics for patients with malignant salivary tumors. $(n=62)$

There was a preponderance of minor SGCs, which comprised $73 \%$ of all cases. As would be expected, these were most commonly localized within the oral cavity $(n=30)$, particularly common at the hard/soft palate junction. The major salivary gland cases were mainly localized to the parotid gland $(n=14)$ with a small cohort of submandibular $(\mathrm{n}=3)$ cancers. The histologic distribution was similar to convention, with the most common tumor types being mucoepidermoid carcinoma (42\%), adenoid cystic carcinoma (18\%), and adenocarcinomas (16\%). Of the cases, $92 \%$ were staged T1-T2 and 79\% were classified as being low to intermediate grade.

Figure 1 demonstrates overall treatment outcomes for this group. The OS and RFS were $91 \%$ and $87 \%$ at five 


\section{Cureus}

years and $80 \%$ and $79 \%$ at 10 years, respectively. For sub-group analyses, five-year rates were calculated. When comparing females to males, both five-year OS ( $93 \%$ vs. $88 \%, \mathrm{p}=0.61)$ and RSS $(82 \%$ vs. $78 \%, \mathrm{p}=0.815$ ) were higher, although this did not meet statistical significance. T-stage corresponded well with the likelihood of disease recurrence, with five-year RFS for T1, T2, and T3 tumors of 92\%, 80\%, and $50 \%$, respectively $(\mathrm{p}=0.042)$. When stratified for tumor site, five-year RFS was highest for oral cavity cancers (96\%) and lowest for cancers arising within the sinonasal tract (50\%); however, given the low numbers, the statistical significance of this finding cannot be well defined.
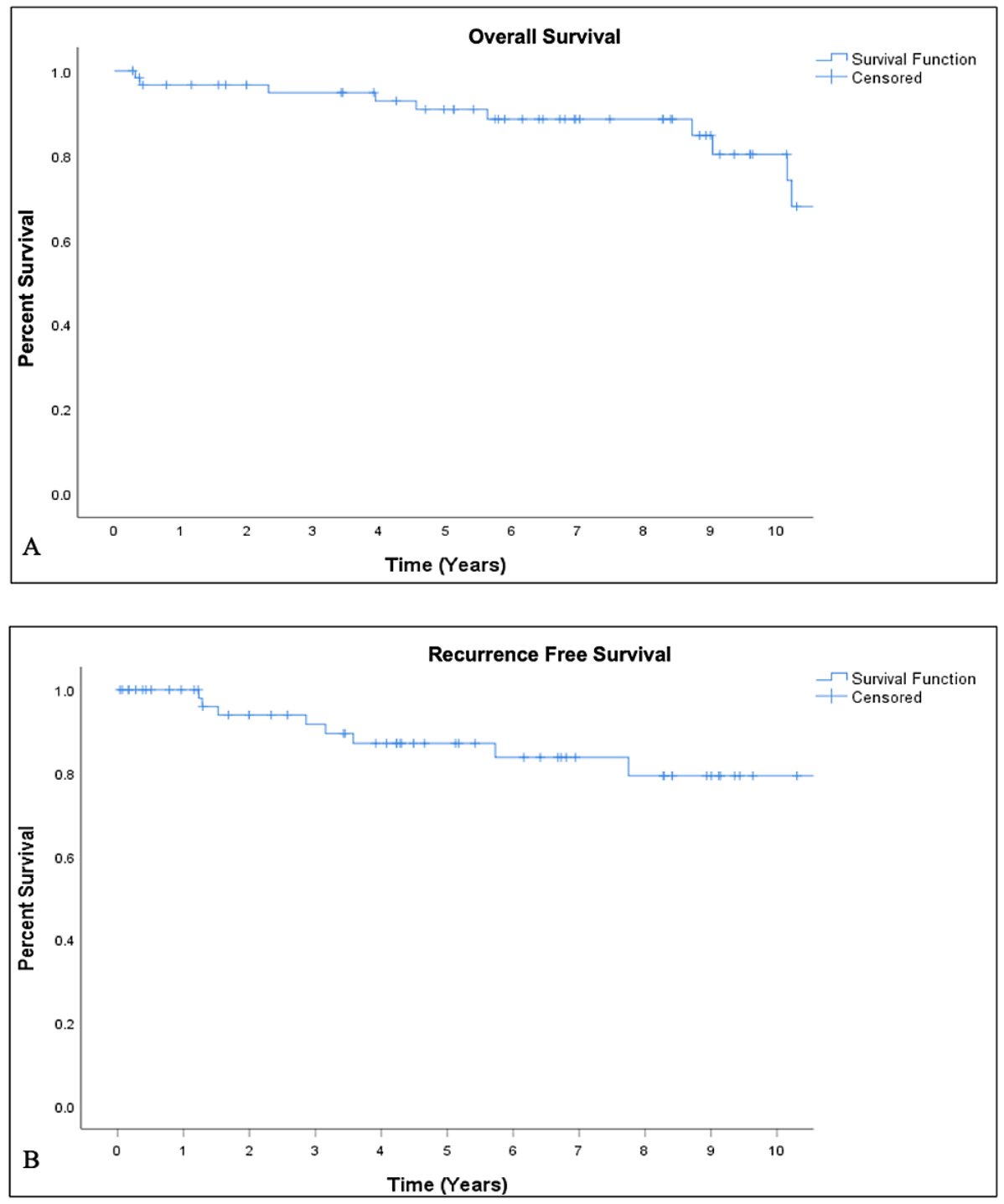

FIGURE 1: Kaplan-Meier curves for overall survival (A) and recurrencefree survival (B)

During the follow-up period, there were a total of 12 episodes of disease recurrence, including a single case of concurrent local + regional failure, occurring in a total of eight patients (Table 2). Characteristics of all eight patients are documented in Table 3. Local, regional, and distant recurrence rates are $10 \%(6 / 62), 3 \%$ $(2 / 62)$ and $5 \%(3 / 62)$ respectively. The average time to first treatment failure was 3.87 years. Interestingly, locoregional failures seem to occur at an earlier average time course than distant disease metastases (3.1 vs 11.3 years). 


\section{Cureus}

\begin{tabular}{|l|l|l|}
\hline Failure Type & Episodes of Failure & Average Time (years) \\
\hline Any & 12 & 6.34 \\
First Failure & 9 & 3.87 \\
Local & 7 & 4.77 \\
Regional & 2 & 4.49 \\
Distant & 3 & 11.25 \\
\hline
\end{tabular}

TABLE 2: Treatment failure characteristics

\begin{tabular}{|c|c|c|c|c|c|c|c|c|c|}
\hline & Age & Gender & Tumor Site & Tumor Grade & Histology & $\begin{array}{l}\text { T- } \\
\text { stage }\end{array}$ & Failure Pattern & $\begin{array}{l}\text { Failure from Surgery } \\
\text { (years) }\end{array}$ & $\begin{array}{l}\text { Neck } \\
\text { Dissection }\end{array}$ \\
\hline \multirow{3}{*}{$\begin{array}{l}\text { Major Salivary } \\
\text { Gland }\end{array}$} & 60 & Female & Parotid & $\begin{array}{l}\text { Mucoepidermoid } \\
\text { Carcinoma }\end{array}$ & $\begin{array}{l}\text { Low- } \\
\text { intermediate }\end{array}$ & 1 & Local & 3.15 & No \\
\hline & 62 & Female & Parotid & $\begin{array}{l}\text { Acinic Cell } \\
\text { Carcinoma }\end{array}$ & $\begin{array}{l}\text { Low- } \\
\text { intermediate }\end{array}$ & 2 & Local & 2.86 & No \\
\hline & $60 \dagger$ & Male & Submandibular & Oncocytic Carcinoma & High & 1 & $\begin{array}{l}\text { Locoregional } \ddagger \\
\text { Distant }\end{array}$ & $7.75,8.19$ & Yes \\
\hline \multirow{5}{*}{$\begin{array}{l}\text { Minor Salivary } \\
\text { Gland }\end{array}$} & 65 & Male & Oral Cavity & $\begin{array}{l}\text { Adenoid Cystic } \\
\text { Carcinoma }\end{array}$ & $\begin{array}{l}\text { Low- } \\
\text { intermediate }\end{array}$ & 1 & Distant & 5.73 & Yes \\
\hline & $32 \dagger$ & Female & Oral Cavity & $\begin{array}{l}\text { Adenoid Cystic } \\
\text { Carcinoma }\end{array}$ & $\begin{array}{l}\text { Low- } \\
\text { intermediate }\end{array}$ & 1 & $\begin{array}{l}\text { Local, Local, } \\
\text { Distant }\end{array}$ & $1.52,13.23,19.84$ & No \\
\hline & 75 & Female & Sinonasal & $\begin{array}{l}\text { Mucoepidermoid } \\
\text { Carcinoma }\end{array}$ & $\begin{array}{l}\text { Low- } \\
\text { intermediate }\end{array}$ & 1 & Local & 1.28 & No \\
\hline & 70 & Female & Sinonasal & $\begin{array}{l}\text { Basal Cell } \\
\text { Adenocarcinoma }\end{array}$ & $\begin{array}{l}\text { Low- } \\
\text { intermediate }\end{array}$ & 3 & Local & 3.58 & No \\
\hline & 72 & Male & Oropharynx & $\begin{array}{l}\text { Salivary Duct } \\
\text { Carcinoma }\end{array}$ & $\begin{array}{l}\text { Low- } \\
\text { intermediate }\end{array}$ & 3 & Regional & 1.23 & No \\
\hline
\end{tabular}

TABLE 3: Demographic, tumor, and clinical characteristics for patients with local, regional, or distance failure $(n=8)$

† Patients with multiple failures

‡ Simultaneous recurrence; however, considered as two separate events for analysis

\section{Discussion}

Much treatment data on non-high-risk salivary malignancies has been derived from large population-based databases, e.g. the surveillance, epidemiology, and end results (SEER) data, with limited information on local/regional disease recurrence [14]. This cohort is thus a useful addition to the literature, as our patients were managed with a uniform treatment algorithm (surgery alone for low-intermediate tumor grade, pN0 or cN0, R0 resection, M0, no lymphovascular invasion, and infiltration) and have maintained prolonged followup. This is essential given a known propensity of SGCs for late recurrence. Chen et al., for example, report a cumulative probability of recurrence at 10 and 15 years after initial SGC treatment to be $13 \%$ and $18 \%$ respectively. Disease-free survival in their population thus slowly declines for at least 15-20 years from the date of initial surgery before reaching a plateau [15]. Park et al., confirmed this finding, as they report a median time to recurrence of 7.71 years after treatment, in their cohort of 240 SGC cases [16]. Short-term disease outcomes must thus be looked at with caution when considering treatment approaches for this group of malignancies. 
Our treatment results with surgery alone are comparable to series that have reported on multimodality therapy for non-high-risk salivary cancers. Armstrong et al., for example, noted five-year survival rates of $82 \%$ for 46 patients with non-metastatic T1 or T2 tumors of major salivary gland treated with combined surgery and postoperative radiotherapy [17]. A similar study by Zbaren et al. compared two patient cohorts with T1/T2 parotid malignancies and suggested an improvement in five-year RFS in those patients receiving adjuvant radiotherapy ( $92 \%$ vs. $70 \%$ ). However, in this series, $40 \%$ of the surgery-only cohort were considered to have high-grade malignancies - which could explain the relatively high failure rate in this group [18].

Appropriate selection of patients with non-high-risk salivary carcinomas to receive surgery alone has the potential to both ensure comparable rates of disease control and avoid the potential adverse effects of adjuvant radiation therapy such as xerostomia, reduced taste, and lymphedema/post-radiation fibrosis. Becker et al. for example evaluated post-therapeutic health-related quality of life in patients with major SGCs treated with various management schemes [19]. Those patients requiring adjuvant radiotherapy had the most dramatic decline in quality of life, specifically negatively impacting physical appearance, activity, recreation, taste, and saliva [19]. In contrast, assuming facial nerve function is preserved, standard parotid surgery has been shown to have a very limited impact on long-term health-related quality of life after the recovery period $[20,21]$.

Our data should be considered favorably when compared to series that have managed SGCs with primary radiotherapy. For example, the University of California, San Francisco (UCSF) experience with primary radiotherapy for salivary malignancies noted five-year and 10 -year OS rates of only $70 \%$ and $46 \%$ [6]. It should be mentioned that $27 \%$ of their patients had $\mathrm{T} 4$ disease, which is not comparable to our series. In a separate series of 67 patients by Holtzam et al., 10-year OS and local-regional control rates for stage I-III SGCs were $63 \%$ and $72 \%$ respectively after radiotherapy alone [22]. Primary surgical management not only provides superior disease control but facilitates pathologic assessment, which is essential for accurate prognostication and treatment planning. With that being said, radiotherapy is a reasonable alternative primary treatment, either for those deemed inappropriate surgical candidates (due to systemic medical comorbidities) or those who prefer non-surgical treatment (after a multidisciplinary treatment discussion) [7].

The above study must be considered in the setting of inherent limitations, specifically related to the inherent bias of retrospective data collection. We have also chosen to present a heterogeneous cohort of patients in regard to the tumor site. This could be potentially problematic, given the theoretical possibility of different disease phenotypes (despite otherwise identical histopathologic features) at separate locations. Tumor grade is another particular challenge in this population, as classification schemes may differ for certain tumor types, often without a clear consensus. This has also evolved somewhat even over the current study period. As a consequence, roughly $17 \%$ of cases were 'unclassified', with some of these entities potentially having high-risk features that would be less appropriate for single modality treatment.

\section{Conclusions}

Salivary gland malignancies continue to pose a rare and particularly unique clinical challenge. Given the extensive heterogeneity at presentation, a variety of clinicopathologic risk variables must be considered in addition to the standard staging algorithms, in order to define the appropriate treatment approach. The goal of treatment optimization should not only focus on disease control but also on limiting post-treatment morbidity when appropriate. Based on our analysis, for appropriately selected low-risk SGCs, surgery alone can produce a high likelihood of long-term disease control.

\section{Additional Information \\ Disclosures}

Human subjects: Consent was obtained or waived by all participants in this study. H. Lee Moffitt Cancer Center and Research Institute issued approval Pro0000923. Animal subjects: All authors have confirmed that this study did not involve animal subjects or tissue. Conflicts of interest: In compliance with the ICMJE uniform disclosure form, all authors declare the following: Payment/services info: All authors have declared that no financial support was received from any organization for the submitted work. Financial relationships: All authors have declared that they have no financial relationships at present or within the previous three years with any organizations that might have an interest in the submitted work. Other relationships: All authors have declared that there are no other relationships or activities that could appear to have influenced the submitted work.

\section{References}

1. Cho JK, Lim BW, Kim EH, et al.: Low-grade salivary gland cancers: treatment outcomes, extent of surgery and indications for postoperative adjuvant radiation therapy. Ann Surg Oncol. 2016, 23:4368-75. 10.1245/s10434-016-5353-6

2. Boukheris H, Curtis RE, Land CE, Dores GM: Incidence of carcinoma of the major salivary glands according to the WHO classification, 1992 to 2006: a population-based study in the United States. Cancer Epidemiol 
Biomarkers Prev. 2009, 18:2899-906. 10.1158/1055-9965.EPI-09-0638

3. Mifsud MJ, Burton JN, Trotti AM, Padhya TA: Multidisciplinary management of salivary gland cancers . Cancer Control. 2016, 23:242-8. 10.1177/107327481602300307

4. Foote FW Jr, Frazell EL: Tumors of the major salivary glands . Cancer. 1953, 6:1065-133. 10.1002/10970142(195311)6:6<1065::AID-CNCR2820060602>3.0.CO;2-0

5. Spiro RH: Changing trends in the management of salivary tumors . Semin Surg Oncol. 1995, 11:240-5. 10.1002/ssu.2980110309

6. Chen AM, Bucci MK, Quivey JM, Garcia J, Eisele DW, Fu KK: Long-term outcome of patients treated by radiation therapy alone for salivary gland carcinomas. Int J Radiat Oncol Biol Phys. 2006, 66:1044-50. 10.1016/j.ijrobp.2006.06.050

7. Terhaard $\mathrm{CH}$ : Postoperative and primary radiotherapy for salivary gland carcinomas: indications, techniques, and results. Int J Radiat Oncol Biol Phys. 2007, 69:S52-5. 10.1016/j.ijrobp.2007.04.079

8. Thomson DJ, Slevin NJ, Mendenhall WM: Indications for salivary gland radiotherapy. Adv Otorhinolaryngol. 2016, 78:141-7. 10.1159/000442134

9. Ali S, Palmer FL, Yu C, et al.: A predictive nomogram for recurrence of carcinoma of the major salivary glands. JAMA Otolaryngol Head Neck Surg. 2013, 139:698-705. 10.1001/jamaoto.2013.3347

10. Poorten VV, Hart A, Vauterin T, et al.: Prognostic index for patients with parotid carcinoma: international external validation in a Belgian-German database. Cancer. 2009, 115:540-50. 10.1002/cncr.24015

11. Terhaard CH, Lubsen H, Van der Tweel I, et al.: Salivary gland carcinoma: independent prognostic factors for locoregional control, distant metastases, and overall survival: results of the Dutch head and neck oncology cooperative group. Head Neck. 2004, 26:681-92. 10.1002/hed.10400

12. Terhaard $\mathrm{CH}$, Lubsen $\mathrm{H}$, Rasch $\mathrm{CR}$, et al.: The role of radiotherapy in the treatment of malignant salivary gland tumors. Int J Radiat Oncol Biol Phys. 2005, 61:103-11. 10.1016/j.ijrobp.2004.03.018

13. Seethala RR: An update on grading of salivary gland carcinomas . Head Neck Pathol. 2009, 3:69-77. 10.1007/s12105-009-0102-9

14. Eppsteiner RW, Fowlkes JW, Anderson CM, Robinson RA, Pagedar NA: Aggressive salivary malignancies at early stage: outcomes and implications for treatment. Ann Otol Rhinol Laryngol. 2017, 126:525-9. $10.1177 / 0003489417702655$

15. Chen AM, Garcia J, Granchi PJ, Johnson J, Eisele DW: Late recurrence from salivary gland cancer: when does "cure" mean cure?. Cancer. 2008, 112:340-4. 10.1002/cncr.23165

16. Park GC, Roh JL, Cho KJ, Jin MH, Choi SH, Nam SY, Kim SY: Incidence and risk factors of late recurrence in patients with salivary gland cancer. Clin Otolaryngol. 2017, 42:416-24. 10.1111/coa.12808

17. Armstrong JG, Harrison LB, Spiro RH, Fass DE, Strong EW, Fuks ZY: Malignant tumors of major salivary gland origin. A matched-pair analysis of the role of combined surgery and postoperative radiotherapy. Arch Otolaryngol Head Neck Surg. 1990, 116:290-3. 10.1001/archotol.1990.01870030054008

18. Zbären P, Nuyens M, Caversaccio M, Greiner R, Stauffer E: Postoperative radiation therapy for T1 and T2 primary parotid carcinoma: is it useful?. Otolaryngol Head Neck Surg. 2006, 135:140-3. 10.1016/j.otohns.2006.03.007

19. Becker C, Pfeiffer J, Lange K, Dahlem KK: Health-related quality of life in patients with major salivary gland carcinoma. Eur Arch Otorhinolaryngol. 2018, 275:997-1003. 10.1007/s00405-018-4914-7

20. Beutner D, Wittekindt C, Dinh S, Huttenbrink KB, Guntinas-Lichius O: Impact of lateral parotidectomy for benign tumors on quality of life. Acta Otolaryngol. 2006, 126:1091-5. 10.1080/00016480600606731

21. Nitzan D, Kronenberg J, Horowitz Z, Wolf M, Bedrin L, Chaushu G, Talmi YP: Quality of life following parotidectomy for malignant and benign disease. Plast Reconstr Surg. 2004, 114:1060-7. 10.1097/01.prs.0000135326.50939.c1

22. Holtzman A, Morris CG, Amdur RJ, Dziegielewski PT, Boyce B, Mendenhall WM: Outcomes after primary or adjuvant radiotherapy for salivary gland carcinoma. Acta Oncol. 2016, 56:484-9. 10.1080/0284186X.2016.1253863 